\title{
Optimum Design of the Volute Tongue Shape of a Low Specific Speed Centrifugal Pump
}

Zhenmu Chen ${ }^{1}$, Van Thanh Tien Nguyen ${ }^{2 *}$ and Ngoc Thoai Tran ${ }^{2}$

${ }^{1}$ Graduate School, Department of Mechanical Engineering, Mokpo National University, Choengnam, 534-729, Korea

${ }^{2}$ Department of Mechanical Engineering, Industrial University of Ho Chi Minh city, 705500, Vietnam

\begin{abstract}
In order to increase pump efficiency and apply an optimum design method of a low specific speed centrifugal pump less than $127\left[\mathrm{~m}, \mathrm{~m}^{3} / \mathrm{s}, \mathrm{min}^{-1}\right]$, twelve kinds of volute casing with the same impeller are designed at impeller blade outlet angle of 34 degree. With each volute tongue shape, there is one volute casing, respectively. The effect of these volute casing shapes is investigated by using computational fluid dynamics (CFD). In this present study the optimum design method in combination of volute tongue shape operating variables for pump performance enhancement is analyzed. Based on design of experiments (DOE) technique, the required experiment trials are determined. The optimization results are pointed out. The parameters chosen for optimum design are the volute tongue angle and the gap between impeller and tongue. The levels for the parametric specification are chosen in the ranges where the pump gets the best efficiency. The results demonstrate that the conventional design is not suitable for a low specific speed. After optimizing the volute tongue, the pump achieves the best performance at $0^{\circ}$ of the volute tongue angle with the appropriate gap between impeller and volute tongue. It is observed that pump efficiency was improved up to $75.01 \%$.
\end{abstract}

Keywords: Volute casing; Tongue length; Optimization; Centrifugal pump

\section{Nomenclature}

H: Head; T: Torque; $\beta_{2}$ : Impeller blade outlet angle; v: Absolute flow velocity; $\eta$ : Efficiency of power plant; $\mathrm{n}$ : Rotational speed; $\mathrm{p}$ : Pressure; Z: Blade number; P: Power; Q: Flow rate/discharge; $\mathrm{N}_{\mathrm{s}}$ : Specific speed; L: Length of volute tongue

\section{Introduction}

A centrifugal pump is one of the kinetic devices, receiving kinetic energy from the rotating impeller when liquid enters the pump. The centrifugal pump action of the impeller accelerates the liquid to a high velocity, transferring mechanical energy to the liquid. That kinetic energy is available to the fluid to accomplish work. Impeller of pump is the key component for pump design strongly affecting on pump performance. Besides, the volute casing is also an important part that needs to be considered [1]. Although the effect of modification to tongue in a centrifugal pump was studied by Dong et al. [2], the optimum volute tongue has never been studied in details before. Therefore, this study discusses mainly the effect of volute tongue shape on pump performance and optimization of that. In order to improve the pump performance, the effects of the pertinent design parameters have been carried out for different cases of primary geometry including the volute tongue angle and the gap between impeller and tongue. After performing design of volute tongue shape, the best shape of volute tongue selected is used for optimizing the tongue length.

\section{Centrifugal Pump Model and Methodology}

\section{Centrifugal pump model}

Table 1 illustrates dimensions and specifications used to design a centrifugal pump model. The main problems needing to be investigated are effect of volute tongue length on performance of the pump and optimum design. Therefore, the volute tongue was redesigned and the impeller was designed and fixed at impeller outlet blade angle $\beta_{2}=34^{\circ}$ as seen in Figure 1.

Different shapes of the volute casing were studied in prior. To determine an original volute casing model, two shapes of volute casing were suggested. The one, which named volute model type 1 , has circular cross-section areas and the other, which called volute model type 2, has sector-shaped areas as shown in Figure 2. The two designed volute casings were used for analyzing by CFD analysis method with the same setting conditions. After finishing the design of the two casing models, cases for each volute casing were run for comparing performances of these volute model types. The original volute casing design, which is the main one before cutting the volute tongue, was carried out by analyzing the pump performance to find out the B.E.P that was used for studying the following volute tongue shape. Table 2 shows the cases which were run. There are six cases with uncut volute tongue, and its internal flow rate was changed from $0.013-0.023 \mathrm{~m}^{3} / \mathrm{s}$.

After finishing the computational run of these cases, the results show that the B.E.P. located at $0.015 \mathrm{~m}^{3} / \mathrm{s}$ of flow rate. In order to

\begin{tabular}{|l|c|}
\hline Specifications & Values \\
\hline Flow rate (design point), $Q$ & $0.015 \mathrm{~m}^{3} / \mathrm{s}$ \\
\hline Head, $H$ & $33 \mathrm{~m}$ \\
\hline Rotational speed, $n$ & $1750 \mathrm{~min}^{-1}$ \\
\hline Specific speed, $N_{s}$ & $127\left[\mathrm{~m}, \mathrm{~m}^{3} / \mathrm{s}, \mathrm{min}^{-1}\right]$ \\
\hline Impeller blade outlet angle, $\beta_{2}$ & $34^{\circ}$ \\
\hline Impeller inlet diameter, $D_{1}$ & $100 \mathrm{~mm}$ \\
\hline Impeller outlet diameter, $D_{2}$ & $272 \mathrm{~mm}$ \\
\hline Volute casing inlet diameter, $D_{3}$ & $280 \mathrm{~mm}$ \\
\hline Discharge diameter, $D_{4}$ & $105 \mathrm{~mm}$ \\
\hline Number of blades, $Z$ & 7 \\
\hline
\end{tabular}

Table 1: Design specifications of the pump model.

*Corresponding author: Van Thanh Tien Nguyen, Graduate School, Department of Mechanical Engineering, Mokpo National University, Choengnam, 534-729, Korea, Tel: +841673887678; E-mail: nguyenvanthanhtien@iuh.edu.vn

Received May 09, 2016; Accepted June 03, 2017; Published June 09, 2017

Citation: Chen Z, Nguyen VTT, Tran NT (2017) Optimum Design of the Volute Tongue Shape of a Low Specific Speed Centrifugal Pump. J Electr Electron Syst 6 226. doi: $10.4172 / 2332-0796.1000226$

Copyright: ( 2017 Chen Z, et al. This is an open-access article distributed under the terms of the Creative Commons Attribution License, which permits unrestricted use, distribution, and reproduction in any medium, provided the original author and source are credited. 


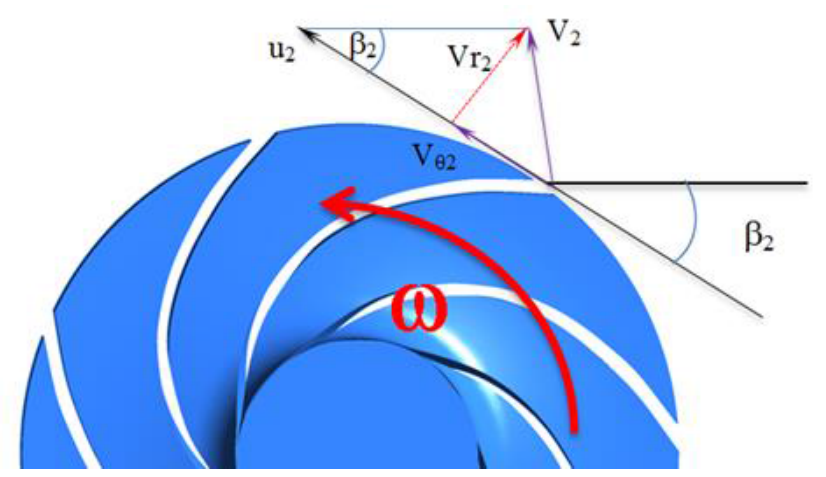

Figure 1: Velocity triangle of the impeller blade.

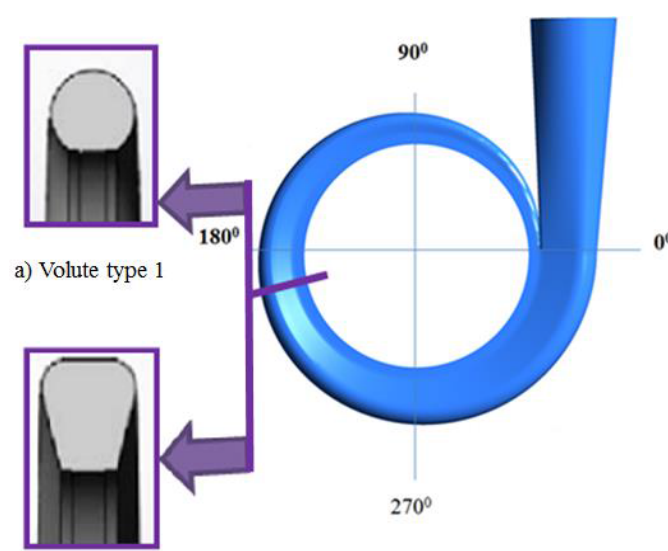

b) Volute type 2

Figure 2: Volute model types 1 and 2.

\begin{tabular}{|c|c|c|}
\hline Volute casing type 1 & Volute casing type 2 & Flow rate \\
\hline case I & case I' & 0.013 \\
\hline case II & case II' & 0.014 \\
\hline case III & case III' & 0.015 \\
\hline case IV & case IV' & 0.017 \\
\hline case V & case V' & 0.021 \\
\hline case VI & case VI' & 0.023 \\
\hline
\end{tabular}

Table 2: Cases of the two volute casings with uncut volute tongue.

investigate effects of a volute tongue angle, in this study, the volute casing tongue was designed by modifying the volute tongue angle. The volute tongue angle is able to be used to determine the tongue length longer when it becomes larger by rotating clockwise or shorter when being smaller by modifying counterclockwise. New volute casings were determined by cutting the volute tongue from the original volute. It means that when the volute tongue angle changes, the volute tongue length will be changed, respectively as shown in Figure 3. In order to follow this method, six volute tongues at $-5^{\circ}, 0^{\circ}, 5^{\circ}, 20^{\circ}, 35^{\circ}$ and $45^{\circ}$ were designed. With each volute tongue shape there have its volute casing. These volute casings were used for investigating by CFD analysis. Cases were determined as shown in Table 3. After analyzing its cases by CFD code, the casing shape with better performances is able to be selected for next studies. In addition, the gap between impeller and volute tongue was designed and investigated. The casing with the best volute tongue angle of previous study was chosen to design three volute casings with various gaps. Figure 4 and Table 4 show the geometry of the volute tongue shape and the gap ratio between impeller and volute

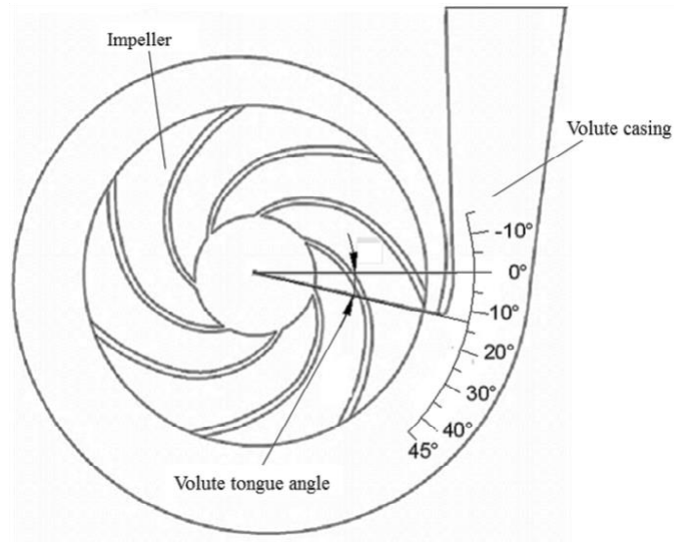

Figure 3: Introduction to the volute tongue angle.

\begin{tabular}{|c|c|c|c|}
\hline No. & Case & Volute tongue angle & Flow rate (kg/s) \\
\hline 1 & case A & $-5^{\circ}$ & 0.015 \\
\hline 2 & case B & $0^{\circ}$ & 0.015 \\
\hline 3 & case C & $5^{\circ}$ & 0.015 \\
\hline 4 & case D & $20^{\circ}$ & 0.015 \\
\hline 5 & case E & $35^{\circ}$ & 0.015 \\
\hline 6 & case F & $45^{\circ}$ & 0.015 \\
\hline
\end{tabular}

Table 3: Cases of the six volute casings type 2 with various volute tongues of the pump in volute tongue angle.

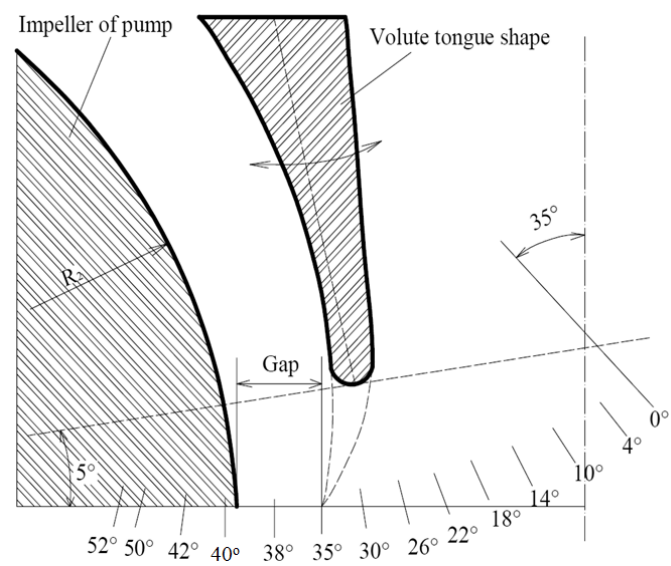

Figure 4: Gap between the impeller and the volute tongue [2].

\begin{tabular}{|c|c|c|c|c|}
\hline No. & Case & Gap angle & Gap/ $\mathbf{R}_{\mathbf{2}}(\%)$ & $\begin{array}{c}\text { Flow rate } \\
\mathbf{Q}(\mathbf{k g} / \mathbf{s})\end{array}$ \\
\hline 1 & case a & $30^{\circ}$ & 11.8 & 0.015 \\
\hline 2 & case b & $35^{\circ}$ & 7.8 & 0.015 \\
\hline 3 & case c & $40^{\circ}$ & 2.7 & 0.015 \\
\hline
\end{tabular}

Table 4: Cases of the volute casing type 2 with various volute tongue gaps.

tongue. It is clear to see that the gap is able to be changed by designers. After the three new volute casings were then analyzed by CFD, the gap with the best performance would be selected as a final design solution.

\section{Numerical methods and boundary conditions}

The fluid domain of the pump model includes impeller as a rotating part, and the volute casing, the inlet duct and the outlet duct are stationary. These parts are assembled settings as a full fluid domain model when the direction of impeller is counterclockwise. CFD analysis 
is a very useful tool for predicting the performance of fluid machinery. This study employs a commercial code of ANSYS to conduct CFD analysis [3]. Tables 2-4 illustrate the cases of the study.

Table 5 shows numerical methods and boundary condition in this study. SST model is adopted as turbulence because of its relatively good convergence in the complicated flow field of turbo machinery in comparison with the other models. Constant pressure at the inlet and averaged outflow at the outlet of the calculation domain are the used boundary conditions. All the calculations are conducted under the conditions of steady state. Approximately $7.7 \times 10^{6}$ elements of hexahedral and tetrahedral grids were used in this analysis as shown in Table 6 .

\section{Design Optimization of the Volute Tongue Shape}

The optimization procedure is carried out in three steps [4]: In the first step a sensitivity analysis is conducted to determine the most important design variables. This is found out help of the Meta model of Optimal Prognosis, refer Most and Will [5]. Next step, the MOP a response surface-based optimization is carried out. On account of this procedure the study for the optimum requires no direct solver run. The followed optimum is verified finally with only a single solver calls. Considering the results of the sensitivity analysis, the most important input variables are used as design parameters within this procedure. Finally, the results of step two as basis, then an optimization is done.

Commonly, size optimization is conducted following the topology optimization to determine the detailed shape of the volute tongue. Since there are two subjects, one is maximum head of pump and the other is maximum torque.

$y(x)=\left|y_{1}(x)+y_{2}(x)+y_{3}(x), \ldots, y_{k}(x)\right| ; x \in \mathrm{S}$ is defined the design space. Find $x_{1}$ and $x_{2}$

To maximize $y_{\text {efficiency }}\left(x_{i}\right)$

Subject to $y_{\text {torque }}\left(x_{i}\right) \leq 600(N . m) i=1,2, \ldots$

There has been a best method for estimating interactive effects among independent variables without implementing factorial design experiments for every level of each the variable [6]. Computing variables and assumption as below

$$
\begin{aligned}
& f=a_{00}+a_{10} x_{1}+a_{11} x_{1}^{2}+a_{22} x_{2}^{2}+a_{12} x_{1} x_{2} \\
& \Leftrightarrow f=d_{0}+d_{1} \xi_{1}+d_{2} \xi_{2}+d_{3} \xi_{3}+d_{4} \xi_{4}+d_{5} \xi_{5}
\end{aligned}
$$

The function of efficiency following $x_{1}$ and $x_{2}$

$$
x_{1}=\mathrm{X}_{1} ; \text { and } \mathrm{x}_{2}=\frac{\mathrm{X}_{2}}{\mathrm{R}_{2}}=\frac{\mathrm{X}_{2}}{136}
$$

\begin{tabular}{|l|c|}
\hline Setting up in CFD & Option \\
\hline Calculation type & Steady state \\
\hline Turbulence model & SST \\
\hline Inlet and Outlet & Total pressure/ Mass flow \\
\hline Impeller rotating direction & Counterclockwise \\
\hline Residual target & $10^{-5}$ \\
\hline
\end{tabular}

Table 5: Numerical methods and boundary condition of the designed pump model.

\begin{tabular}{|l|c|c|}
\hline Domain components & Element No. & Node No. \\
\hline Impeller & $0.9 \times 10^{6}$ & $0.2 \times 10^{6}$ \\
\hline Volute casing & $3.4 \times 10^{6}$ & $0.6 \times 10^{6}$ \\
\hline Inlet and outlet pipe & $3.4 \times 10^{6}$ & $4.9 \times 10^{6}$ \\
\hline Total & $7.7 \times 10^{6}$ & $5.7 \times 10^{6}$ \\
\hline
\end{tabular}

Table 6: Fluid domain of the different components.
Figure 5 introduces to the geometry of the volute tongue. The variable $\mathrm{X}_{1}$ is standing for the volute tongue angle which is able to be modified. The variable $\mathrm{X}_{2}$ is standing for the gap between the impeller and the volute tongue. The gap between the impeller and the volute is made invisible due to simplicity of drawing, but, in this study, its real value is $4 \mathrm{~mm}$, so the gap value after computing is $\left(4 \mathrm{~mm}+\mathrm{X}_{2}\right)$.

Figure 6 shows the flowchart of the optimization processes. The optimization was performed after finishing the study by cases. The CFD results of the pump were then compared with the optimization results of that (Tables 7 and 8).

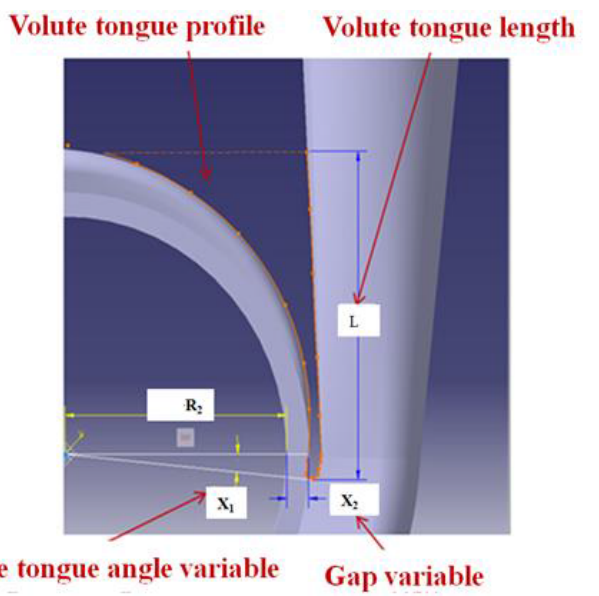

Figure 5: Determination of variables for tongue optimization.

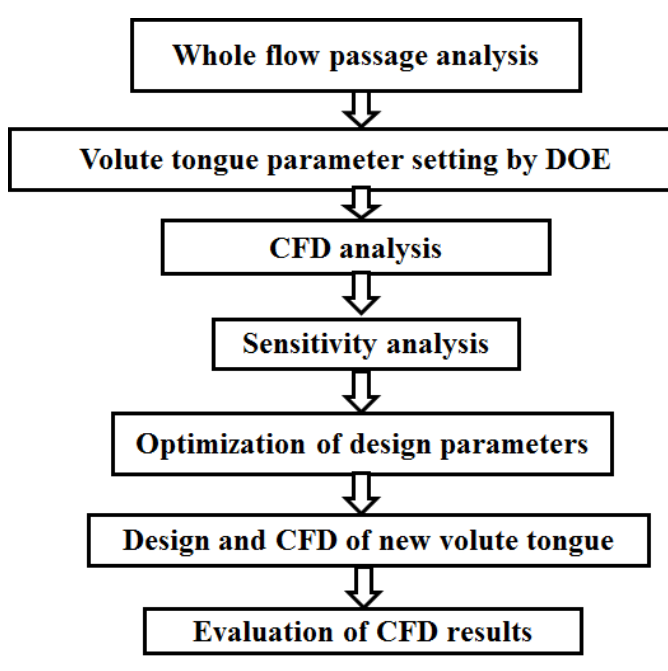

Figure 6: Optimization design flowchart.

\begin{tabular}{|c|c|c|c|}
\hline Sample point & $\boldsymbol{x}_{\mathbf{1}}$ & $\boldsymbol{x}_{\mathbf{2}}$ & $\boldsymbol{f}$ \\
\hline 1 & -5 & 2.7 & 71 \\
\hline 2 & -5 & 7.8 & 68 \\
\hline 3 & -5 & 11.8 & 65 \\
\hline 4 & 0 & 2.7 & 74 \\
\hline 5 & 0 & 7.8 & 73 \\
\hline 6 & 0 & 11.8 & 70 \\
\hline 7 & 5 & 2.7 & 76 \\
\hline 8 & 5 & 7.8 & 73 \\
\hline 9 & 5 & 11.8 & 72 \\
\hline
\end{tabular}

Table 7: Nine sample design points $k=9$ for optimization of volute tongue. 


\begin{tabular}{|c|c|c|c|c|c|}
\hline Sample point & $\xi_{1}$ & $\xi_{2}$ & $\xi_{3}$ & $\xi_{4}$ & $\xi_{5}$ \\
\hline 1 & -5 & 2.7 & 25 & 7.29 & -13.5 \\
\hline 2 & -5 & 7.8 & 25 & 60.84 & -39 \\
\hline 3 & -5 & 11.8 & 25 & 139.24 & -59 \\
\hline 4 & 0 & 2.7 & 0 & 7.29 & 0 \\
\hline 5 & 0 & 7.8 & 0 & 60.84 & 0 \\
\hline 6 & 0 & 11.8 & 0 & 139.24 & 0 \\
\hline 7 & 5 & 2.7 & 25 & 7.29 & 13.5 \\
\hline 8 & 5 & 7.8 & 25 & 60.84 & 39 \\
\hline 9 & 5 & 11.8 & 25 & 139.24 & 59 \\
\hline Maximum & 5 & 11.8 & 25 & 139.24 & 59 \\
\hline Minimum & -5 & 2.7 & 0 & 7.29 & -59 \\
\hline
\end{tabular}

Table 8: Values for variables $\xi_{i j}$ at nine sample points $\mathrm{k}=9$

Applying D.O.E. method, it can be obtained as following

$\left[\begin{array}{cccccc}9 & 0 & 669 & 150 & 622.11 & 0 \\ 0 & 150 & 0 & 0 & 0 & 1115 \\ 669 & 0 & 622.11 & 1115 & 6411.8 & 0 \\ 150 & 0 & 1115 & 3750 & 10368.5 & 0 \\ 622.11 & 0 & 4274.53 & 10368.5 & 622.11 & 0 \\ 0 & 1115 & 0 & 0 & 0 & 10368.5\end{array}\right]\left[\begin{array}{l}d_{0} \\ d_{1} \\ d_{2} \\ d_{3} \\ d_{4} \\ d_{5}\end{array}\right]=\left[\begin{array}{c}642 \\ 85 \\ 4708.5 \\ 12525 \\ 43453.5 \\ 675.5\end{array}\right]$

Solving eqn. 3 (matrix) above and substituting the values in the eqn. 1, it was then obtained to be the quadratic. From the results of $d_{1}$ we have the function as shown

$f=2.927444+0.410639 \xi_{1}+0.304738 \xi_{2}+3.906438 \xi_{3}-0.279986 \xi_{4}+0.02099 \xi_{5}$

$\Leftrightarrow f=2.927444+0.410639 x_{1}+0.304738 x_{2}+3.906438 x_{1}^{2}-0.279986 x_{2}^{2}+0.02099 x_{1} x_{2}$

Solving a robust optimization problem formulated as maximize the function $f$ above. This means that the following function $f_{1}$ (the negative of the function $-f$ ) needs to be minimized.

The noise value which needed to determine the optimized results is computed as the eqn. 4 as following

$$
\frac{S}{N_{\text {ratio }}}=-10 \times \log \left[\frac{1}{9} \sum_{i=1}^{9} f_{1 i}^{2}\right]
$$

The solution $\mathrm{x}\left(\mathrm{x}_{1}, \mathrm{x}_{2}\right)=\mathrm{x}(0,-1.0)$ is selected as the final solution.

\section{Results and Discussion}

When the water flows through the pump, hydraulic losses may occur due to eddy formation in different components as changes in flow direction because of losses in kinetic energy at the discharge of the pump.

Considering only the hydraulic loss, the pump efficiency is calculated by the following equation (5):

$$
\eta=\frac{\rho \times g \times H \times Q}{T \times \omega}
$$

Where $g H$ is specific energy of the centrifugal pump $\left(\mathrm{m}^{2} / \mathrm{s}^{2}\right) ; \rho$ is fluid density $\left(\mathrm{kg} / \mathrm{m}^{3}\right) ; \eta$ is efficiency (\%); $Q$ is flow rate $\left(\mathrm{m}^{3} / \mathrm{s}\right) ; T$ is torque $(\mathrm{Nm}) ; \omega$ is angular velocity $(\mathrm{rad} / \mathrm{s})$.

As a whole, Figure 7 illustrates that the performance curves of two types of the volute casing model increase with a low flow rate, and falls slightly when the flow rate starts increasing larger than $0.015 \mathrm{~m}^{3} / \mathrm{s}$.

After that, from these results the volute type 2 was selected. From Figure 7, it is clear to see that the B.E.P. locates at the flow rate of $0.015 \mathrm{~m}^{3} / \mathrm{s}$ with the pump efficiency of $72.7 \%$. This point is used for investigating effects of volute tongue angle on pump performance later. The effect of volute tongue angle (volute type 2 and $\beta_{2}=34^{\circ}$ ) is shown in Figure 8. It can be seen that the efficiency of the pump is highest at $5^{\circ}$ of the volute tongue angle compared with the other cases. Besides, this figure points out when the volute tongue angle increases larger than $5^{\circ}$, pump performance curves fluctuate slightly. Figure 9 shows

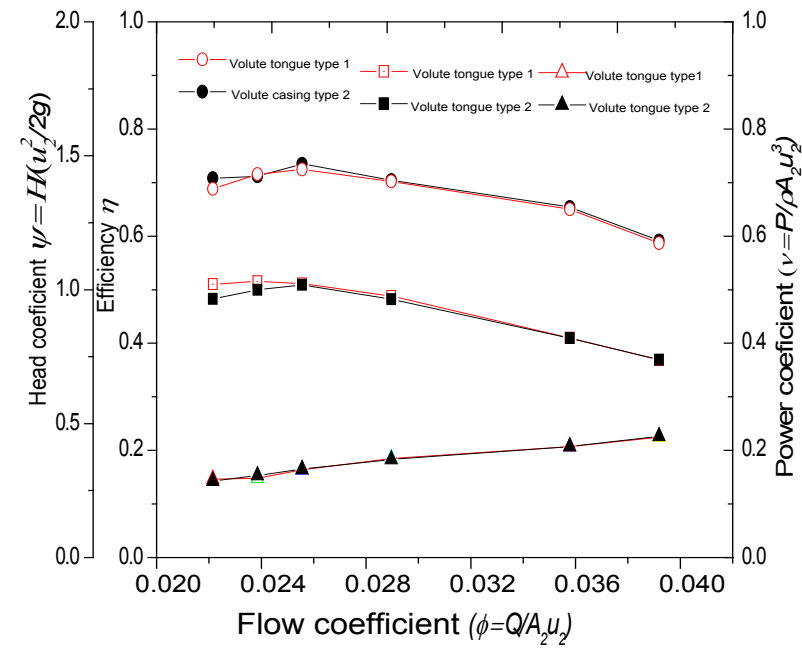

Figure 7: Performance curves of the two types of the volute casing model by CFD analysis.

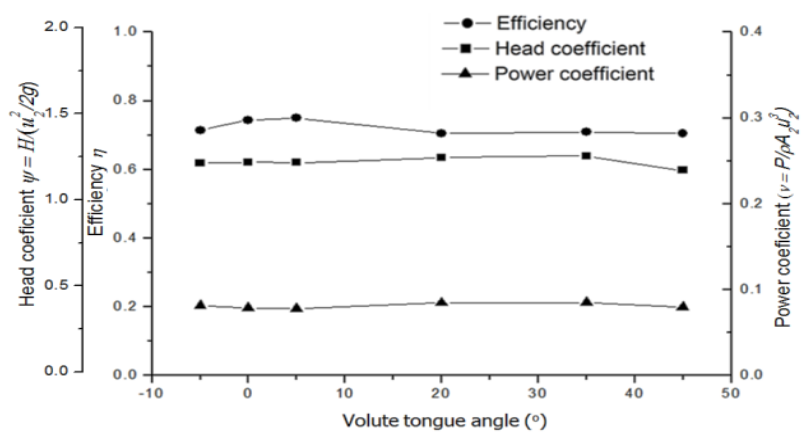

Figure 8: Effect of the volute tongue angle by CFD analysis (volute type 2 and $\beta_{2}=34^{\circ}$ ).

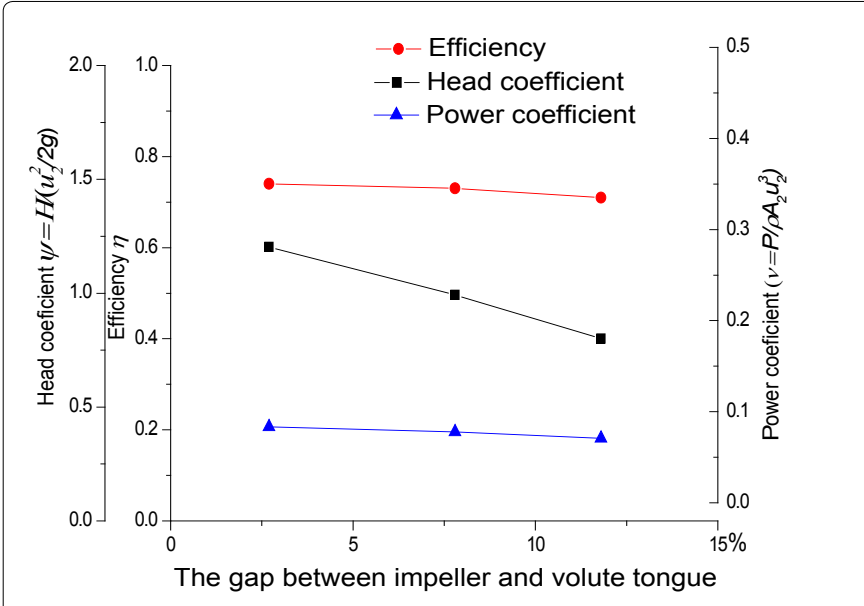

Figure 9: Effect of the gap between impeller and volute tongue by CFD analysis (volute type 2 and $\beta_{2}=34^{\circ}$ ). 


\begin{tabular}{|l|c|c|c|}
\hline \multirow{2}{*}{ Sample point } & \multicolumn{3}{|c|}{ Level } \\
\cline { 2 - 4 } & $\mathbf{1}$ & $\mathbf{2}$ & $\mathbf{3}$ \\
\hline $\mathrm{x}_{1}$ & -15.9600 & -8.7870 & -17.0341 \\
\hline $\mathrm{X}_{2}$ & -13.1480 & -14.2969 & -14.3410 \\
\hline Ignored 1 & -14.0590 & -13.6770 & -14.0500 \\
\hline Ignored 2 & -14.0530 & -14.0721 & -13.6610 \\
\hline
\end{tabular}

Table 9: Design variable and levels.

\begin{tabular}{|c|c|c|}
\hline Parameters and objective & Initial design & Post- optimization \\
\hline$X_{1}$ (Gap) & $7.67 \mathrm{~mm}$ & $7.67 \mathrm{~mm}$ \\
\hline$X_{2}$ (Angle) & $5^{\circ}$ & $0^{\circ}$ \\
\hline$\eta$ & $74.4 \%$ & $75.01 \%$ \\
\hline
\end{tabular}

Table 10: Summary results in comparison.

that the pump efficiency decreases when the gap between impeller and volute tongue increases, respectively. This figure demonstrates that the gap between the impeller and the volute tongue is not more strongly effective on performance of the pump than the volute tongue angle is.

A small gap between the impeller and the volute tongue makes the pump improve its performance [2,7]. It is clear to see that optimum value is $x(0,2.7)$ which was pointed out form the DOE method as seen in Table 9. This means that the volute tongue angle and the gap between impeller and tongue after optimization are $X_{1}=0^{\circ}, X_{2}=3.67 \mathrm{~mm}$ referred eqns. 1 and 2, respectively. It can be seen that the pump efficiency after optimization increases up to $75.01 \%$ as shown in Table 10 . The results show that the gap between impeller and tongue as $7.67 \mathrm{~mm}$ and the volute tongue angle as $0^{\circ}$ are a final option for designers. In Table 10, it can be seen that the volute tongue angle is more strongly effective on pump performance than the gap is.

\section{Conclusion}

The performance analysis for the centrifugal pump model was carried out in detail using CFD methods. From the results of this study, it is observed that the optimum design of volute tongue improved the pump efficiency from $72.7 \%$ (original volute tongue) up to $75.01 \%$.

The results of optimization point out that the centrifugal pump performs best at $0^{\circ}$ of the volute tongue angle and $7.76 \mathrm{~mm}$ gap between impeller and the volute tongue, which are suitable for the parameters and specifications of the pump in this study. Besides, the pump efficiency of the volute casing type 2(fan-shaped areas) is higher than that of the other. A small gap between the impeller and the volute tongue makes better performance of the pump, but if the gap size becomes much smaller, there will be increased the pressure fluctuation that is unwanted and avoided when designing.

\section{References}

1. Stepanoff J (1980) Centrifugal and Axial Flow Pumps: Theory, Design, and Application. China Machine Press, Beijing, China.

2. Dong R, Chu S, Katz J (1997) Effect of Modification to Tongue and Impeller Geometry on Unsteady Flow, Pressure Fluctuations, and Noise in a Centrifugal Pump. J Turbomach 119: 506-515.

3. ANSYS Inc (2015) ANSYS CFX Documentation. Ver. 15, http://www.ansys.com.

4. Kim S (2007) Design Optimization of a Centrifugal Pump Impeller Using DOE and RSM. Master thesis, Seoul: Hanyang University.

5. Most T, Will J (2008) Metamodel of Optimal Prognosis - an Automatic approach for Variable Reduction and Optimal Metamodel Selection. Proceedings of Weimarer Optimierungs-und Stochastiktage.

6. Arora JS (2012) Introduction to Optimum Design. Academic Press, lowa city, lowa

7. Lobanoff VS, Ross RR (1992) Centrifugal Pumps Design and Application, (2nd edn.), Houston, Texas, USA: Gulf Publishing Company. 